\title{
Comprehensive Approach of the Decision Existing Problems of Protection and Stabilization of Water and Soil Resources in Azerbaijan
}

\author{
Rans Aliev ZH* \\ Institute of Soil and Agro chemistry of the nas of Azerb, Azerbaijan
}

Received: 制 June 15, 2018; Published: 畊July 06, 2018

*Corresponding author: Rans Aliev ZH, Institute of Soil and Agro chemistry of the nas of Azerb, Azerbaijan

\begin{abstract}
The article considers the issues of solving the problems of the development of the erosive danger of soil in Azerbaijan, which is why it should be understood that the human mind is unable to change the force of nature, but can only learn and correctly use the laws of nature, use the acting natural force and improve the ways of controlling them. At the same time, in the process of development, methods are struggling with soil erosion in the first stage, which is necessary for studying the causes of occurrence and patterns in its development.

Keywords: Laws of Nature; Terrain Relay; Methods of Struggle; Erosion of Soils; Areals; Patterns of Development of Water-Physical Properties; Basin; Water Regime; Water Balance
\end{abstract}

\section{Introduction}

In purpose of the rational use water resource in condition of the sharp deficit polyvinyl water and all increase water consumption agriculture production, sets the problem of immediate regulation of the sewer in river pool in Azerbaijan (Figure 1). The known that water balance to republic basically depends on hydrology of the mode of the Mountain Rivers. Hydrographic network of the republic counts 8359 rivers, which divide on 5 groups: including - a most small yard, having length less $25 \mathrm{~km}$, small yard with length from 26 before $50 \mathrm{~km}$, average yard with length $51-100 \mathrm{~km}$, greater yard 101-500 km, the greater yard with length $500 \mathrm{~km}$. Also known that hydrology mode is basically connected with condition of the vegetable cover of ground. Follows to take into account that one of the main factors, promoting deterioration of the condition, hydrology of the mode of ground is process degradation topsoil which, broadly wide-spread on mountain declivity of the republic [1].

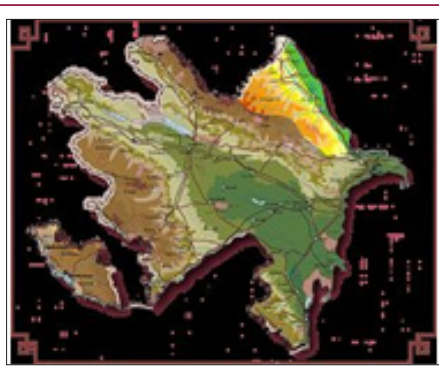

Figure 1.
Topsoil of the Azerbaijani Republic differs the broad range and will comply with the law horizontally-vertical zonal. In this region of the particularities of the climate, the vegetable cover, relief has imposed its imprint on shaping of topsoil. Follows to note that all natural facility are closely bound with each other and change the condition and amount one of the influence on condition all rest. Coming there of natural facility in particular soil, vegetable cover and water facility must be considered in complex, rather than in take-off friend from friend [2].

Relies on that in complex approach of the rational use and guard water resource excessively necessary, since water mode rather sensitive on all change, in surrounding ambience. Herewith it on them powerfully affects. Topsoil and his actual condition are one of main acting factor of the geographical ambience, in which are formed elements of the water balance. Consequently, the interaction of the lithosphere occurs through ground with atmosphere and this is defined by track record of the water mode. Also it must be assumed that water permeability and water retaining ability of ground are characterized with his hydrology importance. Under than specified characteristic render the essential influence upon change the water balance in ground. These characteristic finally define the intensity of the forming the surface sewer, degree of the development and geometries of the spreading erosion processes on territory, amount to losses of water on evaporation and on infiltration and underground water spare. 
In mountain and foothill region republics under influence anthropogenic factor topsoil subject to in one or another degree erosion process [3].

At present erosion land form $41.8 \%$ from the whole area of the lands of the republic. The fight with speed destructive erosion of ground, guard of ground by warning and eliminating the reasons origin wash off and blower ground, by checking on already developing process to erosions, recovering the fertility damaged water and wind erosion ground must be built, coming from naturally-history natural regularities, changed and changing under influence of production activity of the person, coming from knowledge of the regularities in development erosion processes, knowledge's of the laws of the development of the soil fertility [4]. In decision of the problems of increasing of the fertility erosion ground follows to understand that human reason unable to change power of the nature, but only can learn and it is correct to use the laws of the nature, use acting natural power and improve the ways of management them. Herewith in step of development methods fights with erosion of ground in the first queue necessary to study the reasons of the origin and regularities in her development [5].

We know that developments erosion process to bring about deterioration water-physical characteristic of ground, promoting breach water balance element. The known that, in mountain zone of the republic are found headwaters of the rivers, water mode beside which basically hang from actual conditions water assembly pool. Follows to note that river sewer is formed mainly in is blazed-meadow, is blazed-timber and in is blazed-husbandry zone. Herewith founding result of the studies of the row scientist (E. Salaev, R. Mamedov, K. Mamedov, H. Mustafaev, G. Mamedov, B. Budagov, M. Babaev and row others), these zones of the following groups divides on typical factor [6]. So for instance: It is Blazedmeadow zone - on relief and gradient to surfaces, differs presence rather extensive areas with steepness declivity 20-400 and more. Here depth local base to erosions varies in value $800-1000 \mathrm{~m}$, but in some places $1000-1500 \mathrm{~m}$. Scientist have proved; proven that for is blazed-meadow zone typical alpine and

subalpine vegetation, which forms denominated дерновый layer, being important factor guard to surfaces of ground from destruction and demolition, but in the same way promotes the regulation of the water mode [7].

Founding result called on multiple studies, becomes firmly established that at present before $60 \%$ is blazed-meadow ground in one or another degree to subject to erosions. In consequence of escalated fall out, which is accompanied the intensive development erosion process on these lands. Productivity rubbed on year pasture very low, flora composition to grassy vegetation grew worse. Here many valuable and juicy stern plants are changed rubbish, poisonous and uneatable animal, which as a rule and weakly protect the surface of ground from wash off and erosion [8]. The studies is proved that that in alpine zone of the mountain part of republic erosion processes run enough intensive, than in sub alp to width. Under small power of topsoil in given zone vegetation is characterized rather low grass stand. Unlike alpine, in sub alp to width significant development has gained plane and ravine erosion. The studies called on taught (H. Mustafaev, K. Alekperov) becomes firmly established that on south-east declivity by steepness 200 , where fall out was conducted in accordance with rate, surface of ground was covered sod, at intensities rain $2.74 \mathrm{~mm} / \mathrm{min}$. sewer 5.6 $\mathrm{mm}$ and factor his 0.20 wash off ground did not exist. In the opinion of authors, the small sewer and absence wash off are explained in the same way presence sod layer, which enlarges the roughness to surfaces, lengthens the contiguity layer water and ground [9].

In year pasture of the republic under intensive pasturage, sod a decay that bring about wash off surfaces of ground, in consequence of which grows worse and her water permeable, herewith falling out atmospheric precipitation weakly seep deep and occurs shaping the surface sewer that promotes the reinforcement erosion processes. Accepting in attention of the development erosion processes in timber zone to happen to the conclusion that, our republic, being few forests by mountain country, differs from nearby. As of SSD general area all timber arrays in republic (the report material 1995) formed before $1 \mathrm{mln}$. Ha i.e. takes up to $11 \%$ whole territory, under than here $90 \%$ forests are located in mountain terrain.

Consequently, for growing agriculture cultures on these lands, is required 9-10 thou.m3/ha irrigation of water [10]. Relies on that mountain wood of the republic gain using high effective water protect and soil protect action, which is proved result of the called on studies of the row scientist (B.H. Aliev, 2000) of the Republic. Author becomes firmly established that on essences of urgency water save and soil protect importance wood appears in many events by more essential economic factor, than their direct use [11]. In meadow-forest to width, at presence on surfaces of ground of the timber bedding and vegetation, due to good water permeable, precipitation intensive seep in ground. The destruction and demolition of ground occurs here rather moderate.

The studies called on under the direction of prof. H. Mustafaev is installed that on south-west declivity mountain in region by steepness before 200 at presence of grassy vegetation and timber bedding by power $1.2 \mathrm{sm}$, when presenting $25.2 \mathrm{~m} / \mathrm{min}$. water, surface sewer has formed $3.6 \mathrm{~mm}$ and at factor his 0.14 ; closed ground was absent. Meantime, in consequence of escalated fall out and fighter vegetation, timber bedding and sod layer to here subject to destruction. Under intensive anthropogenic influence, under fighter wood in particular and escalated fall out, timber bedding and grassy cover are oppressed on steep declivity of the surfaces of ground, getting, under direct influence of the atmospheric precipitation herewith and exists his closed. On south-west declivity of the mountains of the republic by steepness 200 where vegetation and timber bedding were removed, at intensities rain $2.52 \mathrm{~mm} /$ min. surface sewer has formed $16.8 \mathrm{~mm}$ and at factor of the sewer 0.66 closed was is $3.3 \mathrm{t} / \mathrm{ha}$. Analyzing result called on by author of the studies possible to note that only when removing the vegetable cover in meadow-forest belt, sewer increased in 5 once and closed was significant. Characteristic of that lower is blazed-timber width is characterized presence of the greater areas with declivity in 15-200 limits and steep slope, depth local base to erosions which, varies in value (400-800) $\mathrm{m}$ and more. Here timber vegetation 
fighter to a considerable extent and is presented rare sprouts wood. In many places on south and west steep declivity, timber vegetation is destroyed completely and ground protects from wash off only rare grass vegetation, falling summer. In consequence of which, here erosion processes in contrast with the other zone wide-spread more broadly.

Also, it is necessary to note that on steep declivity often exists formation a ravine, shower, disposits, topsoil is presented fair and powerfully erosion difference. In rare oak-hornbeam wood and on abandoned area, because of sharply lowered water permeable, precipitation weakly seep in ground: is formed surface sewer, which destroys and take ground. Follows to note that in wood by fullness 0.7 at factor of the sewer 0.11 , closed ground did not exist. Herewith in rare oak-hornbeam wood, sewer was significant, where ground is powerfully washed off (the factor of the sewer 0.76 ) and closed forms $14.4 \mathrm{t} / \mathrm{ha}$. Thence possible draw a conclusion that chop down wood, destruction year pasture and plough lands on declivity sharply reduce erosion stability of ground and lead to intensive wash off; grow worse the fertility of ground and water mode. In purpose guard resource and fights with powerfully developing process to erosions on these area necessary most quick development and introduction complex actions in particular few intensive irrigation, agro ameliorative, phyto ameliorative, agro techniques and others [12].

\section{Conclusion}

a) Deforestation, destruction of summer pastures and plowing of lands on the slopes dramatically reduce erosion resistance of the soil and lead to intensive wash-out; soil fertility and water regime are deteriorating.

ISSN: 2574-1241

DOI: $10.26717 / B J S T R .2018 .06 .001358$

Rans Aliev ZH. Biomed J Sci \& Tech Res

(C) This work is licensed under Creative

Submission Link: https://biomedres.us/submit-manuscript.php b) In order to combat erosion, it is necessary to implement complex measures, in particular phytomeliorative, agro technical and hydro technical.

\section{References}

1. Abduev M (2003) Speed land reclamation clay saline soil Azerbaijan. Baku, pp. 250.

2. Aliev RA (1955) Rational use winter pasture Azerbaijan and way of their improvement, Baku, pp. 32.

3. Aliev BH (1994) Drip irrigation in Azerbaijan, pp. 189.

4. Bashirov NB (1982) Efficiency drip and under soil-centre of the irrigation grapes and small disperse of moisture culture of tea on declivity lands in Azerbaijan. Azerbaijan, p. 9-16.

5. SY Jika Baku (1966) The general scheme of the complex use and guard water resource Azerbaijan SSR. Baku, Azerbaijan

6. The Association "Soyuzvodproekt" Moskva (1983) Scheme complex use and guard water resource pool r. Samur and adjoining rivers find time; seize a moment-Sumgaitchay in Azerbaijan SSR.

7. Zakharov PS (1971) The erosion of ground and measures of the fight with her. Pub-in "Ear", pp. 191.

8. Zakharchenko IG (1978) The rotation and balance of the nutrients and change physics' characteristic main types of ground of the country in husbandry. Vashnil, p. 5

9. Mirkin VM, Hagieva FM (2001) Management fertility ground agro system approach. Baku, pp. 216.

10. Mustafayev H (1990) Efficiency of the mineral fertilizers on background ceolit under winter barley on mountain erosion grey-brown ground. The south-east declivity Big Caucasus. Baku, pp. 20.

11. Awls LA (1985) The Modern concepts of management fertility ground, Fertility of ground: Problems of the study, models M p. 3-12.

12. Shakuri BK (2007) The intensity of the biological processes of ground of the system vertical zonal south, south-east declivity Big Caucasus and their pathology under influence exogenous processes, Baku.

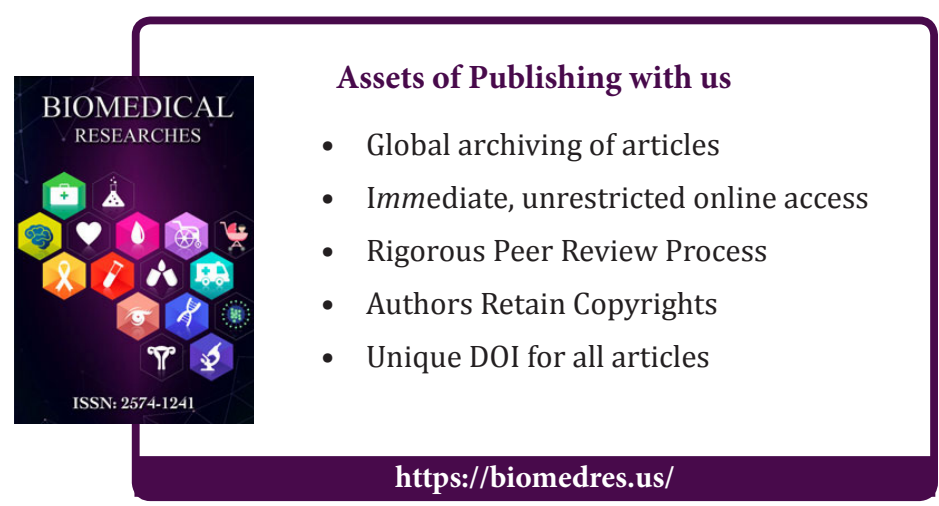

